\section{Are learning sets learned? Or: Perhaps no nature-nurture issue has any simple answer}

\section{E. W. MENZEL, JR., and CHARLES JUNO \\ State University of New York, Stony Brook, New York}

We shall make no attempt to answer each of Schrier and Thompson's (1984) many criticisms of our report (Menzel \& Juno, 1982). Instead, we shall first list some of the points on which we actually concur with these authors (usually despite their apparent opinions to the contrary), and then we shall expand upon a few details mentioned in our report, which they overlooked. If any loose ends still remain, we request readers to consult, or reread, our original report and Kamil and Yoerg's (1982) overview of the relations between learning and foraging behavior.

The points of agreement are as follows: (1) Our report is not directly concerned with interproblem improvement in performance during the course of our observations. (We could detect no such improvement. Insofar as direct comparisons of data are warranted, our animals seemed to start where marmosets might be expected to asymptote. And if we must demonstrate interproblem improvement before talking about "learning sets," is not the doctrine that learning sets are learned unfalsifiable?) (2) Our report does not contain conclusive evidence that the difference between our data and data from "real" learning-set studies is attributable to testing the animals in their home cage as a group instead of in isolation. (3) The ability for one-trial learning in our subjects does not prove that the genesis of this ability involved no trace of slow, gradual learning at any point in their lifespan. (4) It is hard to imagine that test-naive primates of any and all species would perform as our animals did. (5) Our methods are so different from those of Harlow that precise comparisons of the numerical data would be of dubious validity. (6) Students of learning set should not feel compelled to adopt the methods and concepts of foraging theorists if they do not want to. (7) The data we presented do not, as such, prove that animals were cognitive geniuses. (8) Slow, gradual learning is not necessarily maladaptive or unknown outside of the laboratory. (9) Our animals did not learn all that could conceivably be learned about an object in a single trial. (10) Few of our ideas are original with us. (11) The empirical phenomenon of interproblem improvement in performance has by now been more than amply demonstrated, even though the full explanation for

The authors' mailing address is: Department of Psychology, SUNY, Stony Brook, NY 11794. this phenomenon is not yet in hand. (12) Our analyses of group performance are not very orthodox. (Unless, of course, one treats the group as a whole as if it were a single individual. And, coincidentally, we also presented data that we construed as strong evidence of learning on the part of individual group members. Schrier and Thompson do not mention these data.) (13) Laboratory research is a good thing and can teach us a lot that we could not learn otherwise. (14) Readers who did not read the references that we cited might possibly infer, incorrectly, that learningset theorists today still hold that performance on learning-set tasks is a good index of so-called general intelligence. (15) We did not provide a comprehensive review of the history or theory of learning set.

The principal purpose of our report was to describe, for the benefit of scientists in general, rather than only specialists in learning, how group-living Saguinus fuscicollis behave with respect to one another and with respect to novel objects. It extended a previous study on this same general topic (Menzel \& Menzel, 1979) and also tested whether the behavior of these animals supports the by now venerable hypothesis that so-called win-stay and lose-shift strategies with respect to objects, however they are acquired, are a sufficient basis for one-trial objectdiscrimination learning (cf. Schusterman, 1962). We reword this hypothesis to read as follows: Any set of mechanisms, however they might originate, is in principle a sufficient basis for one-trial associative object-discrimination learning, provided that it leads animals to investigate new objects or classes of objects that might or might not contain food, to return to those that contained food on last encounter, and to not return (or return less readily) to those that did not. We stated explicitly that our own position was not an argument either for or against empiricism or nativism. To be more precise, whether or not animals possess a sufficient set of win-stay and lose-shift mechanisms (defined as above), precisely what these mechanisms consist of, how they originally developed and evolved, and whether or not the animals can be said to possess a high degree of so-called general intelligence are four logically independent questions that should not be confused or confounded with one another. Schrier and Thompson completely ignore this statement.

Not only in direct connection with this point, but also because of the crucial theoretical significance they themselves attach to the use of simultaneous rather than "go/no-go" procedures, we shall now expand on another statement that they overlooknamely, our explicit mention of the fact that we replicated our results with simultaneous as well as "go/no-go" procedures. To be sure, the simul- 
taneous discrimination data were not reported in detail. (They are currently in preparation for publication.) But if readers doubt the ability of $S$. fuscicollis on this score, they may examine the previous study (Menzel \& Menzel, 1979) on which our own study was based. Our procedure for the test of simultaneous ("associative") discrimination was similar to that of Menzel and Menzel's first experiment, except that, instead of introducing only a single object on each trial, one that never contained food, we introduced two new objects on every other trial, one of which contained food. Once a new pair of objects was introduced, we left them in the test room, so that from one problem to the next the number of objects escalated until there were 30 objects in the room simultaneously. The test room was adjacent to the animals' home cage, and they were allowed to remain in it for up to 15 min per trial. One trial was given each day.

The results showed that, from the first problem, the animals learned in a single trial the appearance of the objects, their locations, and whether or not they contained food. As in our "go/no-go" tests, whichever individual had discovered the food on Trial 1 was the most apt to lead the move to the food object on Trial 2 and to respond to it the longest; each group member was on one or more occasions the "leader" here; and no comparable Trial 1 versus Trial 2 reliability in social approach order occurred with nonfood objects. What better ("yoked-control") evidence could one have for learning on the part of individuals? The group used for this experiment was the same one we used previously; but, except for discriminating which objects contained food, as well as other parameters of the objects, they did nothing that Menzel and Menzel's (1979) test-naive group had not also done. The youngest group members were not (as Schrier and Thompson note) very apt to be the discoverers of the food on Trial 1; however, they scored the highest of all group members on the number of occasions on which they succeeded in obtaining food.

Admittedly, our "trials" are not directly comparable to those of Harlow. They were set at a fixed duration of time that was longer than the time a whole group of animals ordinarily take to respond to a novel object or situation before abandoning it without interference on our part. Without doubt, one might wipe out "one-trial learning" entirely by making one's "trials" short enough. But, by the same token, one could wipe out slow, gradual learning and objectperception, too-and where would that leave anyone?

Individual $S$. fuscicollis do not, coincidentally, very often stay at an object that contains a fair amount of food until the food is gone; typically, they grab a bit of it, run off with it for several meters, and then return to the same object after an infant steals the food from them or after they themselves have consumed it. On these return trips, they might bypass (and ignore) any number of other objects. They assuredly seem to learn at least the location of food within a matter of seconds, and to remember it for at least several minutes, within our macroscopic, group-appropriate "Trial 1." We would bet that they also learn something about the visual appearance of the object. Would anyone care to bet otherwise?

Even it were true, as Schrier and Thompson claim (without any relevant evidence for their claim), that our marmosets showed only "fast associative learning" but not the use of "abstract hypotheses," it would be irrelevant to our own position. It also still leaves them with the following problems: Why should marmosets that are tested with Harlow's procedures initially show no one-trial object-discrimination learning of any sort? Is this representative of what they could do at the same time in other contexts? Does their eventual achievement of one-trial learning constitute the "emergence" of a new ability or simply the reappearance of an old one? Our own answers to these questions still stand, at least in the light of the currently available evidence. We do not view them as any more critical of Harlow's basic assumptions than, say, Jarvik (1956), who addresses the same issues.

We feel under no more obligation to use Schrier and Thompson's "standard learning parameters" before discussing our data in the light of Harlow's theory than students of learning set feel compelled to study cats in a puzzle box, chimpanzees in outdoor test situations, or pigeons in an operant chamber before discussing the pertinence of their findings for Thorndike's, Kohler's, and Skinner's theories, respectively, about the nature and genesis of animal intelligence. We do not profess to know precisely what parameters account for the differences between our data and previous data; but most readers of Harlow's works (for a summary, see Harlow \& Mears, 1979) would surely be as surprised as we if social separation, testing group-living animals in isolation, and species-specific aspects of responsiveness are of no consequence-especially for younger animals, who have not as yet been forced by social pressures and other factors to shift from their predominantly social strategies of acquiring food to other, relatively asocial strategies.

The fundamental question is, of course, whether the data support the conclusions we drew from them. We submit that they do, and that Schrier and Thompson have simply overlooked much of the data and misunderstood our position.

\section{REFERENCES}

Harlow, H. F., \& MeArs, C. (1979). The human model: Primate perspectives. New York: Wiley. 
JARV1K, M. E.(1956). Simple color discrimination in chimpanzees: Effect of varying contiguity between cue and incentive. Journal of Comparative and Physiological Psychology, 49, 492-495.

KAMIL, A. C., \& YoERG, S. I. (1982). Learning and foraging behavior. In P. P. G. Bateson \& P. H. Klopfer (Eds.), Perspectives in ethology (Vol. 5, pp. 325-364). New York: Plenum.

Menzel, E. W., \& Juno, C. (1982). Marmosets (Saguinus fuscicollis): Are learning sets learned? Science, 217, 750-752.

Menzel, E. W., \& Menzel, C. R. (1979). Cognitive, developmental and social aspects of responsiveness to novel objects in a family group of marmosets (Saguinus fuscicollis). Behaviour, 70, 251-278.

Schrier, A. M., \& Thompson, C. R. (1984). Are learning sets learned? Animal Learning \& Behavior, 12, 109-112.

Schuste RMAN, R. J. (1962). Transfer effects of successive discrimination-reversal training in chimpanzees. Science, 137, 422-423.

(Manuscript received May 16, 1983;

revision accepted for publication September 13, 1983.) 